\title{
Chinese Management Research Needs Self-Confidence but not Over-confidence
}

\author{
Li, Xin; Ma, Li
}

Document Version

Accepted author manuscript

Published in:

Asia Pacific Journal of Management

DOI:

$10.1007 / \mathrm{s} 10490-018-9562-3$

Publication date:

2020

License

Unspecified

Citation for published version (APA):

$\mathrm{Li}, \mathrm{X}$., \& Ma, L. (2020). Chinese Management Research Needs Self-Confidence but not Over-confidence. Asia Pacific Journal of Management, 37(2), 481-498. https://doi.org/10.1007/s10490-018-9562-3

Link to publication in CBS Research Portal

\section{General rights}

Copyright and moral rights for the publications made accessible in the public portal are retained by the authors and/or other copyright owners and it is a condition of accessing publications that users recognise and abide by the legal requirements associated with these rights.

\section{Take down policy}

If you believe that this document breaches copyright please contact us (research.lib@cbs.dk) providing details, and we will remove access to the work immediately and investigate your claim.

Download date: 26. Apr. 2023

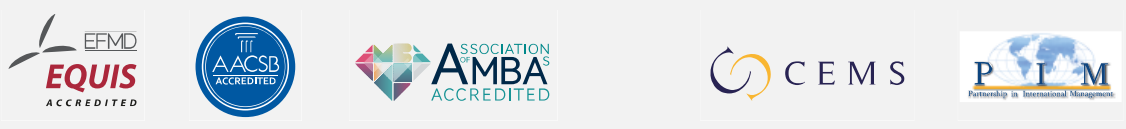




\title{
Chinese Management Research Needs Self-Confidence but not Over-confidence
}

\author{
Kin Li and Li Ma
}

Journal article (Accepted version*)

\section{Please cite this article as:}

Li, X., \& Ma, L. (2018). Chinese Management Research Needs Self-Confidence but not Over-confidence. Asia Pacific Journal of Management. 001: 10.1007/s10490-018-9562-3

This is a post-peer-review, pre-copyedit version of an article published in Asia Pacific Journal of Management. The final authenticated version is available online at:

DOl: https://doi.org/10.1007/s10490-018-9562-3

* This version of the article has been accepted for publication and undergone full peer review but has not been through the copyediting, typesetting, pagination and proofreading process, which may lead to differences between this version and the publisher's final version AKA Version of Record. 


\title{
Chinese management research needs self-confidence but not over-confidence
}

\author{
Xin Li \\ Copenhagen Business School, Denmark \\ xl.int@.cbs.dk \\ Li Ma \\ Guanghua School of Management, Peking University, China \\ lima@gsm.pku.edu.cn
}

Accepted version On 15 January 2018

Asia Pacific Journal of Management

\begin{abstract}
Chinese management research aims to contribute to global management knowledge by offering rigorous and innovative theories and practical recommendations both for managing in China and outside. However, two seemingly opposite directions that researchers are taking could prove detrimental to the healthy development of Chinese management research. We argue that the two directions share a common ground that lies in the mindset regarding the confidence in the work on and from China. One direction of simply following the American mainstream on academic rigor demonstrates a lack of self-confidence, limiting theoretical innovation and practical relevance. Yet going in the other direction of overly indigenous research reflects overconfidence, often isolating the Chinese management research from the mainstream academia and at times, even becoming anti-science. A more integrated approach of conducting Chinese management research is recommended. Specifically, it is recommended that researchers can focus on phenomena salient in China and follow rigorous scientific methods, as illustrated by a few exemplary studies using the Chinese context. In this way, Chinese management research can advance if it becomes more self-confident in its study and application but not over-confident.
\end{abstract}

Keywords: management, research, antiscientific, China, self-confidence, overconfidence, rigor, relevance, scientific method 
Management research faces two challenges that the natural science disciplines generally do not. First, management research needs to satisfy both requirements of academic rigor and practical relevance (Van de Ven, 1989). It needs to stick to the rigor of any science (social sciences included) discipline such that it can be accepted in academia and faithfully renders the theory and evidence at hand (Ahlstrom, Lamond, \& Ding, 2009; Van de Ven, 2007). At the same time, it needs to be up-todate and relevant to practice such that practitioners are able to obtain insight from the research, much as in other professional sciences such as medicine and engineering (Van de Ven, 2007). Second, as a consequence of the relevance requirement, management research needs to address not only universality (appealing globally) but also particularity (for local stakeholders).

In this view, in spite of the fine progress of Asia research in general, and Chinese management research in particular (Peng, 2007), many challenges remain. Given the fact that the mainstream management research was developed and largely tested in North America, two opposite paths of research historically have existed for Chinese management scholars to follow. On the one hand, scholars could simply pursue their academic careers just as they were working in a North American university. Alternatively, they may exert their time and talent in topics more salient in China but less salient in the Western mainstream. We have observed a large number of Chinese scholars choosing either one of the two paths above. However, both paths face the challenges, albeit in different ways, regarding their contribution to knowledge accumulation as well as to practical import. Some of the so-called indigenous research lacks academic rigor and reflects "armchair thinking" only. At the same time, some more "global" research fits a publishable academic rigor, but its relevance on the East Asian context is often dwarfed by the emphasis on being accepted by the broader field.

In analyzing these issues, this paper adopts the perspective of confidence and summarizes seemingly contradictory trends using the same perspective. Specifically, some researchers simply lack self-confidence (Meyer, 2006), while some others have perhaps become over-confident, reflected in a pedantic assertiveness, with some not paying sufficient attention to the relevant established literatures (Ahlstrom, 2017). This paper thus holds that both can be detrimental to the development of Chinese management research (Meyer, 2006; Zhou \& Wei, 2015). More importantly, several exemplar studies are examined which utilize the Chinese context effectively. This demonstrates that an appropriate level of confidence can be achieved by applying rigorous methods into novel Chinese contexts to contribute to the accumulation of management knowledge and its practical import (Fang, 2003, 2010; Young, Peng, Ahlstrom, \& Bruton, 2003).

\section{Lack of self-confidence in Chinese management research is detrimental}

What topics should be pursued by Chinese management scholars? The answer to this question seems obvious to many managers (and consultants) who work in China. 
Many respond that they have many specific problems to solve and they hope that business scholars can offer them concrete and inspiring solutions to their problems. Others seek to apply the rigor of social sciences such as economics or psychology in conjunction with management theory to samples in China to further demonstrate the robustness of (general) theories and methods (Li, Ashkanasy, \& Ahlstrom, 2014; Zhao, Gu, Yue, \& Ahlstrom, 2013) However, many Chinese management scholars have left some of them somewhat disappointed, particularly on the practical and policy sides of the ledger (Ahlstrom, Bruton, \& Lui, 2000; Huang, 2010).

"Mainstream" journals tend to ignore indigenous Chinese topics

Management research in China has proliferated and improved significantly in the past two decades. This is not only demonstrated by the research findings relevant to China published in foreign journals conducted by foreign and overseas Chinese scholars as well as scholars working in Mainland China. The academic associations such as the International Association for Chinese Management Research (IACMR) and Asia Academic of Management (AAoM) have positively impacted the scholar community and communication. Some papers published in the most highly-regarded Chinese language management academic journals such as Management World (from the Development Research Center of the State Council in China) or Acta Psychologica Sinica (from the Chinese Psychological Society and the Institute of Psychology, Chinese Academy of Sciences), as well as English language publications from China such as Nankai Business Review International also follow the rigorous research methods and double-blind review procedures. The status quo of management research in China has been improved significantly throughout these years by embracing the rigorous research methods (Meyer, 2006; Tsui and Lyu, 2015; Tsui, 2004, 2006; Li and Zhang, 2016) and writing standards (Ahlstrom, Bruton, \& Zhao, 2013).

With the recent achievements in mind, the development of management research in China still is seen as lacking in a number of areas (Ahlstrom, Chen, \& Yeh, 2010; Fang, 2010. For example, only a very few indigenous constructs were proposed or tested (e.g. Lai, Lam, \& Liu, 2010; Tsui, 2006). Rather, many papers tend towards academic jargon in their theory and hypothesis development, often simply focusing on topics dominant or prevalent in mainstream management and international business journals (Zhang, Ju, \& Ma, 2014). Huang and Bond (2012: 513) very pessimistically concluded: "There is nothing more American than research on Chinese organizational behavior." Their ideas expressed the worry that the majority of Chinese management scholars are simply following the so-called mainstream management research, that is, the largely American paradigms of management scholarship (Donaldson, 1995).

This phenomenon's origin lies partly in the lack of self-confidence, not only in the minds of researchers, but also in the minds of the academic institutions' leaders such as university presidents and business school deans. Many academic institutions pursue internationally recognized indices such as citation counts and H-Indices of individuals - again, generally dominated by North American or Western European institutions. Meyer (2006) pointed out an ironic situation that "a leading Chinese or Russian scholar who influenced thousands of students, business persons and policy 
makers in his or her own country, may well achieve a SSCI [Social Sciences Citation Index] count of zero - especially if he or she is writing in a language other than English" (p. 133). Obviously, the "Made in America" indices were never intended to cover the impact of scholars who teach and write in other languages.

The situation now could be even more of a concern than Meyer (2006) described. In fact, some leading business schools in China are not relying on the two counts (the count of SSCI citations or the count of the number of published papers in SSCI journals); even more selectively, they count numbers in more narrowly defined lists of leading journals such as the FT-50 (from the Financial Times) and UTD-24 (from the University of Texas at Dallas). Based on our interactions with scholars in leading business schools in China, almost all these business schools have their own "journal lists" (influenced by the preceding two Well-known lists), and the academic journals on the lists are categorized at different levels according to their importance to researcher evaluation at a given school. For example, the top ranked management journals are most likely the seven: Academy of Management Journal, Academy of Management Review, Administrative Science Quarterly, Journal of Applied Psychology, Management Science, Journal of International Business Studies, Organization Science, and Strategic Management Journal. A school that emphasizes entrepreneurship more may rank Journal of Business Venturing and Entrepreneurship Theory and Practice quite high (though both are also FT-50 journals). As pointed out by a number of scholars (e.g., Meyer, 2006), these journals are "born American," even the Journal of International Business Studies and the Journal of World Business that focus on international business issues. Although in recent years many of these journals' editorial teams have tried to expand global authorship and global topics, these journals still have a very long way to go to shift gears toward more truly international research (here, being international means foreign to North America, including Asian topics).

An obvious consequence of highly regarding these North American journals is that the China-special topics in management can be difficult to publish in these journals, though it is easier today than in years past. For example, one established accounting researcher teaching in a major Singapore university reported his own disappointing experience. Even though he had published dozens of papers in leading accounting journals, his papers with the word "China" or "Chinese" in titles were often desk rejected by these same journals that he had already published in.

Sometimes, the desk rejection occurred just a few hours after his submission. This is because the mainstream academic journal -- most likely reviewed and administered by the mainstream scholars - were just not interested in what they perceived to be strictly Chinese topics (Meyer, 2006). The difficulty of publishing indigenous research in leading journals has been shared by a number of scholars.

Quite a few have further pointed out that Asian business schools in general and Chinese business schools in particular, could actually assign quality regional journals such as Asia Pacific Journal of Management and Management and Organization Review as top tier journals and offer equal credit to their professors for publishing in 
these two journals much the same as with papers published in the previously mentioned prestigious journals (Meyer, 2006). However, to our knowledge, no leading business school in China has proved confident enough to accept such a practice as it would significantly deviate from the mainstream North American business schools.

Organizational theories offer some explanation as to why the educational institutions are so conservative. Norms of behavior and assessment tend to be developed and promulgated by the early established players in a field (Garud \& Ahlstrom, 1997). Late comers most likely lack the confidence and capabilities to challenge the institutional norms and assessment criteria, and thus can only accept whatever criteria of evaluating them, in spite of the apparent rationality of doing so (Nair \& Ahlstrom, 2003; Scott, 2013). Indeed business schools first thrived and gained prominence in the United States, and the business schools eventually set up the criteria of excellence among their professors, including indicators of mainly publications in a limited set of journals (Mintzberg, 2003). Relatedly, other social organizations such as Financial Times and QS.com also rank business schools based on indicators such as publications in those journals. Late comers need to gain legitimacy in the field such that they have to accept the criteria already existing for the business schools (DiMaggio \& Powell, 1983). Only by gaining the legitimacy can the late coming business schools obtain the status and resources they need in their own institutional environment (Magee \& Galinsky, 2008).

As a result, the business schools in other regions (such as Europe, Korea, and China) are criteria-accepting late comers. In order to achieve international status, they accept the criterion of excellence as publications in the leading (English-language) journals. Obviously, the late comers lack the confidence of modifying existing criteria and establishing their own criteria. However, some disruptive innovators boldly change the rules and norms how the existing players play the game to succeed (Christensen, Raynor, \& McDonald, 2015). For example, Steve Jobs liked to cite Henry Ford's ideas on not asking customers what they want, because other than a gasdriven car, most people would have been immersed by the existing rules and simply have asked for a faster horse (Isaacson, 2011). For disruptive innovators such as Jobs, they need to change the rules played by the current players in the industries such that they can change their status from being followers into pioneers and leaders in a given field. Such lessons are also very instructive to the business schools in emerging economies such as China seeking to improve their international reputations.

Neglected research topics

The lack of confidence in Chinese management research leads to the unfortunate consequence that Chinese management research often lacks practical relevance as well as theoretical innovations. Mimicking the American practices has led to more published research, including papers in highly regarded American and British academic management journals. However, many important topics specific to the Chinese context are not published to the broader academia, or not studied at all. For example, the social security fund in China has accumulated about two trillion Yuan 
( $\$ 310$ billion) so how to manage and make use of the fund effectively is a critical question to China that may have an impact on the well-beings of hundreds of millions of Chinese people. Yet, no single paper on this topic has been published in the mainstream finance journals in North America. In addition, the state-owned enterprise reform and restructuring are extremely important to China because these enterprises play essential roles in Chinese economy. However, possibly due to the perception in the mainstream that these enterprises are too idiosyncratic, very few such papers are published in the mainstream highly-ranked journals (Bruton et al., 2015).

Furthermore, China is home to more than 200 million migrant workers who live and work in cities as "temporary stayers," far from their famial homes. What factors influence their work motivation, working ethic, work-life balance, job turnover, decision to stay in cities, and decision and career choices? Such topics are extremely important to management practice in China and possibly contribute to the "mainstream" knowledge creation as well, given the number of migrant and guest workers around the world. The consequence of paying insufficient attention to important questions relevant to Chinese management practices is that there has been limited theoretical contribution to global management knowledge after several decades of Chinese management research (Jia, You, \& Du, 2012; Peng, 2005; Tsui \& Lyu, 2015; White, 2002).

Issues regarding theoretical and practical contributions

By following the mainstream academia, Chinese management research will generate similar results to the North American mainstream - however, even the American management academia has been criticized for a lack of relevance to the real world and for being timid in terms of theoretical innovation. Indeed in his 1993 presidential address of the Academy of Management, Donald Hambrick (1994) criticized the status quo at that time of the Academy, which could also be true today. Employing a counterfactual argument, he asked "what if the Academy of Management mattered." Hambrick argued that if we had traveled back to the past and saw the history without us, "we will find that things might have worked out very, very well without us [i.e., the Academy's annual conference participants/the Academy's members and their work]." Hambrick criticized the situation that management scholars write and talk to colleagues within the Academy only, but pay little attention to the outside - the audience who really matters. More than two decades have passed and a number of initiatives (e.g., Van de Ven, 2007) have been proposed in the academia, but the situation is not relieved in the academic management field as yet.

In addition, theoretical innovation in the past few decades has also fallen behind the 1970s when scholars focused on important questions (Colquitt \& Zapata-Phelan, 2007). Sutton and Staw (1995: 383) asked "the reader to consider whether the evidence provided by people such as Freud, Marx, or Darwin would meet the empirical standards of the top journals in organizational research." Right now, the journals are paying more attention to the technical nuances such as robustness checks and reliability, but not the importance of the research questions (ironically, the robustness or reliability of the SSCI indices themselves are seldom questioned in the 
university administrative system at all when evaluating Chinese management researchers). When the mainstream is suffering from both theoretical innovation and practical relevance, it is may be less than wise for Chinese business schools to thoughtlessly follow the North American model (Jia et al., 2012).

In that regard, the Chinese academia of management research still follows the North American trend, leading to no better outcome than the situation in North America. In fact, many Chinese distinguished scholars, business leaders and governmental officials have, for many times in many years, called for more relevant management research in China. However, such calls are not institutionalized yet in the business schools' incentive systems. Chinese management scholars still have to pay a prominent part of their attention to the institutional forces - performance appraisal policies and assessment criteria in their schools - and continue the seeking of publications in the mainstream western journals. I believe that the underlying reason lies in the Chinese academia's lack of confidence in creating a China-relevant criterion for publication and impact excellence (thus it seems safe to follow the past successful players, i.e., the North American business schools).

\section{Over-confidence in Chinese management research is also detrimental}

While the current mainstream, "American" paradigm, of management research that emphasizes heavily on academic rigor is often criticized for lack of practical relevance and offering limited theoretical innovations (Colquitt \& Zapata-Phelan, 2007; Hambrick, 1994; Weick, 1989), finding a viable alternative approach is not easy. A number of scholars have called for conducting indigenous research focusing on China-relevant topics (Li, 2012; Li, Leung, Chen, \& Luo, 2012; Li, Sekiguchi, \& Zhou, 2016), which can possibly produce more interesting and inspiring findings (e.g., Tsui, 2007).

Acknowledging that there are various contextual differences between China and the West, indigenous management research that can strive for novel theory building and testing is a necessary and valuable endeavor (Bruton, Zahra, \& Cai, forthcoming). Rather, the concern is that some opinions and assumptions in China research are overconfident and assertive in exaggerating the China-West differences to the exclusion of the China-West similarities, and thus may fall into the trap of being anti-scientific due to the lack of academic rigor (as critiqued by Li, 2014, 2016). In fact, indigenization for the sake of indigenization has been characterized as potentially alarming ( $\mathrm{Li} \&$ Zhang, 2016).

Sometimes, over-confidence may turn into dogmatism without careful research. For example, while many people tend to overstate the cultural differences between China and the West and attribute international differences in business conducts to national culture, Ahlstrom and Wang (2010), in a rigorous analysis tracing the recent intellectual history of studies on entrepreneurial capitalism in Chinese (and overseas Chinese) business, point out the weakness of an almost didactic reliance on Confucianism. That is, Confucianism was seen by many as a sole explanatory 
variable for entrepreneurial capitalism in ethnic Chinese communities in particular to the near exclusion of other cultural and institutional influences.

There are two aspects of such a dogmatism. One aspect argues that Chinese phenomena are rather complex that Western analytical theories are inapplicable or insufficient for explaining them. This view has been critiqued as "Chinese exceptionalism" by Peng (2005: 133). The other aspect claims that some elements of Chinese culture and way of thinking are unique and often superior to the Western counterparts for dealing with some management problems. This can be termed Chinese ethnocentrism. This paper argues that both Chinese exceptionalism and Chinese ethnocentrism are flawed and detrimental for the healthy development of Chinese indigenous management research, and are both examined in more detail below.

\section{Critiquing Chinese exceptionalism}

As China is both a developing country and transition economy with a strong cultural heritage and historical legacy (Ahlstrom, Levitas, Hitt, Dacin, \& Zhu, 2014), Chinese exceptionalism has a large number of supporters, including researchers from fields such as economics, political science, management studies, and history, just to name a few. However, in a number of fields, we observe that the Chinese exceptionalism has faced challenges from researchers in the selfsame fields (e.g., Ahlstrom, 2010; Jia, 2016; Singh, 2007; Zhou \& Wei, 2015). It is argued here that the Chinese exceptionalism lacks the logic and evidence to rule out alternative explanations, as shown in the examples below from a number of disciplines.

In economics, a number of Chinese economists believe that Chinese economy is so complex that anyone who succeeds in explaining it deserves a Nobel Prize for Economic Science (Zheng, 2012). Some others even stated that only Chinese economists are able to well explain Chinese economic issues (Zheng, 2012). To some people, the continued rapid economic growth in China is a miracle or partly myth. However, to many other researchers, rapid Chinese economic growth is not mysterious or difficult to explain (Ahlstrom, Nair, Young, \& Wang, 2006; McCloskey, 2013). A huge domestic market for consumption (including consumption for the first time of many products, e.g., mobile phones, computers, motorcycles, cars, houses, etc.), expanding international markets for cheap made-in-China products, state-led heavy investments in manufacturing and infrastructure, stable government system favoring economic development, new venture creation with both local and foreign investment (Ahlstrom, 2010), and industrial upgrading from technological learning and leapfrogging are some major reasons for rapid, albeit uneven economic growth in China (Huang, 2010). All of these are well explained by economic growth theories, such as the Harrod-Domar model (Domar, 1946; Harrod, 1939), Lewis' (1954) dual sector model, Solow's $(1956,1957)$ neoclassical growth model, Romer's $(1986,1990)$ endogenous growth theory, and work on formal (Acemoglu \& Robinson, 2012) and informal (McCloskey, 2010) institutional theory and economic growth. 
In political sociology, some scholars argue that Chinese state's legitimacy to rule is based on its economic performance rather than any of the three sources of legitimacy or authority identified by Max Weber (1978), that is, traditional, charismatic, and legal-rational. A number of scholars argue that Weber's classification, while illuminating, has some problems and is hard to be applied in empirical analysis (Yang \& Zhao, 2015). In response, Zhao (2009) proposes an alternative classification by dropping charismatic legitimacy and adding performance as a major dimension of state legitimacy. Yang \& Zhao (2015) argue that economic performance has increasingly become the primary basis of state legitimacy of the Chinese communist government. However, in Weber's conception of charismatic authority, a charismatic leader must also demonstrate extraordinary charisma to his followers. China's economic successes of the past four decades clearly demonstrate to the Chinese people that the ruling party has the capability (charisma) to correct its mistakes and continue the economy's rapid development, which reinforces Chinese people's acceptance of the Communist Party's authority. Performance legitimacy, viewed in this sense, is indeed a form of charismatic authority (Zhou \& Wei, 2015). Thus, the Weberian framework fits fairly well with the Chinese context.

In management studies, again, some scholars see Western theories fall short of offering sufficient explanations of some phenomena in China but their arguments are challenged by alternative explanations. For example, in examining why successful Chinese private entrepreneurs pursue memberships of the People's Congress or People's Consultative Conference at different levels, Li and Liang (2015) assert that Western theories of life career development are inadequate due to their egocentric nature while Confucian doctrine of role transition is more suitable due to its inclusion of a prosocial component. However, as Xin Li (2016) points out, although Li and Liang's analysis offers a novel alternative, it is flawed for two reasons. The first is that they confound the prescriptive nature of Confucian ideology and the reality of political participation among Chinese entrepreneurs. What they fail to see is the decoupling between the classical Confucianism and the secular version of Confucianism (Leung, Koch, \& Lu, 2002), namely, the real behaviors of Chinese people might be different from the prescriptions of Confucianism. The second is that they fail to see that the political strategy theories (Hillman \& Hitt, 1999; Jia, 2016; Li, Meng, \& Zhang, 2006) can well explain why businessmen in China and other countries enter politics. Very simply, having membership in the People's Congress or People's Consultative Conference offers the entrepreneurs and their companies' competitive advantages in business.

As the examples above illustrate, Chinese exceptionalism may misguide scholars to neglect possible explanations that are already well supported in the mainstream literature, while relying too much on some special Chinese explanations. Such an effort is detrimental for the development of Chinese management research. In addition, Chinese exceptionalism may also misguide scholars to use Chinese classic philosophical or cultural sources inappropriately while ignoring extensive empirical research collected elsewhere on related topics. 
In conducting indigenous research, many Chinese scholars tend to base their analysis on Chinese classical texts, such as the Analects of Confucius, Dao De Jing, and Zhong-Yong. In these classical texts, there are plenty of valuable ideas including prescriptive norms. When quoting those prescriptive norms, we need to keep a bit skeptical of them without carefully looking at the real behaviors of Chinese people and the various conditions that such prescriptions may or may not operate. In fact, much of classical Chinese philosophical literature focuses more on the prescription of idealized behaviors rather than on the description of actual behaviors of people (Ma \& Tsui, 2015). In addition, they fail to specify the conditions under which their prescriptions may work or may not (Ahlstrom et al., 2010). This is particularly true for leadership prescriptions which recent research has shown need careful specification of conditions such as the difficulty of the situation and the maturity of the followers (Li, Chun, Ashkanasy, \& Ahlstrom, 2012; Liden, 2012). The traditional Chinese philosophies also often failed to define the constructs clearly, analyze the conclusions in a logical ways, and discuss the boundaries of their ideas (Ma \& Tsui, 2015).

\section{Chinese enthnocentrism}

The assertiveness aspect of dogmatism is reflected in the belief that Chinese traditional philosophy has some unique elements, making it superior to Western philosophy of science for guiding Chinese indigenous management research ( $\mathrm{P}$. Li, 2012, 2013, 2014, 2016). Similar to the ideas in exceptionalism, such calls for developing indigenous Chinese management theories also are hard to generate meaningful empirical studies or invite academic dialogues.

For example, "Yin-Yang balancing" is sometimes viewed as a unique epistemology of Chinese philosophy that is claimed to be "more sophisticated (rather than "naïve") than all dialectic logics for paradox management since it is the only system that can truly accommodate and appreciate paradox, and it has the potential to absorb all Western systems into a geocentric (East-meeting-West) meta-system" (Peter P. Li, forthcoming, italics added). It may be possible that the ideas embedded in "Yin-Yang balancing" are different from the ambidexterity approach (Gibson \& Birkinshaw, 2004; O'Reilly \& Tushman, 2013), it is hard to anticipate that the possible superiority of Yin-Yang and its subtleties are easy to test empirically.

Another example often used to talk about the Chinese superiority is the so-called Chinese philosophy's methodology of "Wu" that is defined as "intuitive imagination for insight via metaphor; 悟 or 悟性 in Chinese" in contrast to logical analysis adopted by Western philosophy (P. Li, 2016: 50). It is claimed that logical analysis can only be used to evaluate or verify existing knowledge, novel insight or new knowledge can only be created by $W u$; and therefore, "Chinese philosophy of wisdom" is superior to Western philosophy of science for guiding knowledge creation (P. Li, 2016). However, if the Wu-based cognition is image-based analogy (“取象比 类”) (Wang \& Li, 2017: 13), then, it is very similar to the notion of metaphor in the Western literature, which refers to "a number of metaphorical devices - such as internal analogues, images, prototypes, and the like" (Pylyshyn, 1993: 545, italics in 
original). The metaphor or analogy approaches are used numerous times in the Western world as well, including by those who advanced scientific discoveries (Berggren. 1962, 1963; Gentner, 2003; Gentner \& Jeziorski, 1993) as well as in the social sciences in terms of disciplined imagination (Weick, 1989). As stated by Ortony (1975: 45), "At least since the time of Aristotle metaphor has aroused the curiosity of thinkers." Danesi (1993) and Bartha (2016) see Aristotle's comparison theory of metaphor sets the stage for all later discussion of metaphors and theories of analogical reasoning. Gentner \& Jeziorski (1993: 448) point out that Aristotle acknowledged that "the perception of similarities between disparate things could be a source of special insight". Thus, Wu-based cognition characterized by metaphorical thinking is not unique to Chinese as Gentner (2003: 106) points out that "Analogical thinking is ubiquitous in human cognition". Furthermore, Berggren (1962: 237) concludes that "truly creative and non-mythic thought, whether in the arts, the sciences, religion, or metaphysics, must be invariably and irreducibly metaphorical."

As demonstrated by the two examples above, the Chinese ethnocentralism sticks to the special Chinese elements in some classic writings but often ignores the broader literature and very similar concepts to compare the Chinese elements with the rest of the world in scientifically rigorous approaches.

In sum, over-confidence, in the form of either exceptionalism or ethnocentralism, leads to problems in Chinese management research. In short, it represents indigenization for the sake of indigenization and neglects comparison with existing research. Theoretically, such a stream is very likely to isolate the ideas from the large body of literature addressing similar questions. It is highly possible that over-emphasis on the Chinese specialty in management may lead to a discarding of rigorous research methods in logical theory building and research procedures. We believe that China-relevant research can improve significantly only if scholars are self-confident but not over-confident or assertive.

\section{What to do next? Recommendations to Chinese management scholars}

Merits from the two extreme opinions

Above we have criticized the two relatively widely-chosen options. In a nutshell, the first option featured by a lack of self-confidence simply follows the mainstream American approach, which is characterized by highly pursuing academic rigor with low concern for practical relevance; in contrast, the assertive indigenization option is characterized by closely relevant to the Chinese specialty on thinking and cognition (but not necessarily the practical relevance) but lacks academic rigor. Although we criticize the two relatively widely-chosen options and deem them detrimental, we also believe that both options above have their own merits. It is on their merits that can spread and guide us forward. We believe that the debates about Chinese management research has helped the Chinese management academia a lot, though it has to be guided by clear and fuller discussions of epistemology, ontology, and an understanding of the relevant literature in a given area. 
First, even though the "pure American" approach does not pay much attention to Chinese indigenous questions, this approach does help to train management researchers in methodology, research design, and paper organization (Ahlstrom, 2015). At the first time when management was thought as something valuable to study in China in the early 1980s, the active management researchers in China that time had little opportunity to be trained in methodology. In fact, even from the time when the previous round of commentaries were written and published (Meyer, 2006; Peng, 2005; Tsui, 2004; White, 2002), Chinese academia of management has improved a lot in the technical aspects regarding research. Specifically, the methodological education in Ph.D. courses now in leading Chinese business schools are already close to the better business schools in North America. More and more management scholars who obtained their doctoral education in Mainland China can publish in top-tier American journals in recent years as leading authors, indicating that the methodological education has been fruitful. The seeking for acceptance by the mainstream academia also helped build the academia from the academic world rather than by authoritarian hierarchy. This progress can help guide Chinese management research to thrive in the future.

Thus, what has been done in the past two decades should be applauded. At least, the majority of Chinese management scholars in this generation has improved from the previous generation's dominant "armchair thinking" paradigm into rigorous and logical theory analyses, model building, and hypothesis testing. However, at this stage, the lack of self-confidence and the practical implications of American journals' dominance need to be changed.

Second, even though the assertive opinions often look down at the wellestablished research paradigm in management, those opinions do remind us that many China specific questions are important to study. In fact, today's management practices in China have been extremely dynamic and often innovative. Take e-commerce innovation for example. Chinese internet companies are very innovative in their business models, different from the familiar former practices of copying what has been done in the United States. Even The New York Times reported that American counterparts need to learn from the Chinese companies. In addition to innovation in business models, many Chinese companies have also made strides in technological innovation. For example, some Chinese companies have exceled in the areas of battery and electric cars, super computers, and fifth generation telecommunication, and so forth. Indeed, Chinese companies in recent years are not only following the long-time so-called "advanced management practices from the developed economies," but also exploring their own ways of doing business.

Thus, we are not calling for a "middle-ground" between the two extremes. On the contrary, we believe a more appropriate way of doing indigenous Chinese management research is to study China specific and relevant questions using rigorous methods. This is the same as what Oded Shenkar (2017) proposed as a hybrid approach that features research inspired by Chinese special phenomena targeting at international audience. That is, to conduct meaningful research, not only rigorous in 
methods but also relevant to the field - the active management practices in China. When important and indigenous topics that are also closely relevant to practice topics are pursued in Chinese management research, and at the same time, rigorous methods are used, meaningful scholarly dialogues will start. Such research inspires other research and thus contributes to the management field (Donaldson, 1995).

\section{We are not expecting too much: Illustrations of exemplary research}

Specifically, we recommend the scholars interesting in Chinese indigenous research to closely watch the management field and know the real phenomenon, and at the same time, conduct rigorous research to initiate meaningful dialogues with other scholars, including the "mainstream" American academia (e.g., Fang, 2012; Jing \& Van de Ven, 2014; Luo \& Child, 2015). In fact, many activities in the real fields are very interesting to address and many traditional norms and values in China need further theoretical explanations, but are waiting for prepared and intellectually ready eyes. This call is the same as previous calls on contextualization (Meyer, 2006, 2014; Tsui, 2004, 2006), and here we offer a few concrete examples. We believe the few indigenous studies discussed below are very insightful in integrating academic rigor and Chinese specialty. Their "success" shows that we are not expecting too much.

For example, Zhixing Xiao and Anne Tsui's (2007) research on broker status on employee benefits successfully compared the Chinese context with the North American context and expanded social network theory. Originally, social network theory developed in the American context predicts that brokers or organizational members who possess the structural hole positions (i.e., people who are critical to connect other people) obtained benefits such as rank, bonus, and salary (cf. Xiao \& Tsui, 2007). However, extending the theory to the Chinese context where collectivistic culture dominates, Xiao and Tsui found that brokers actually received lower salary and lower bonus than non-brokers. These results are exactly reverse of what was found in the United States. In addition, in organizations with high level of commitment, structural holes are negatively correlated with salary and bonus, but the results are non-existent in organizations with low level of commitment. Putting together, their research tests the limitation of social network theory in China and clearly draws the boundary condition of the theory developed in America.

The Chinese are also famous for accepting paradoxes, as shown in the Yin-Yang idea. Yan Zhang and her colleagues originally studied caring leadership, but their interviews with organizational members indicate that the idea of caring leadership did not intrigue the Chinese employees at all. In comparison, what the members like the most is the leaders who can balance the seemingly contradictory "both" and "and" aspects of management or leadership. Thus, they developed the construct of paradoxical leader behavior. With the novel approach of measuring the paradoxical aspects using questionnaires, their paper was published in top-tier American journal and has been widely cited (Zhang, Waldman, Han, \& Li, 2015).

Kwok Leung's research on conflict management also was based on the Chinese 
context and advanced the mainstream literature. He saw that the Western dual-concern model focuses exclusively on the outcome of conflict, and realized that in the Chinese context, people care a lot about harmony in interpersonal relationships. Thus, he and his colleagues first built a model with the Chinese harmony idea incorporated (Leung, Koch, \& Lu 2002). Later on, he and his collaborator juxtaposed the Chinese and Western models to build an integrated model that is supposed to be theoretically universal (Leung \& Brew, 2009), which was later on tested empirically in China and Australia (Leung, Brew, Zhang, \& Zhang, 2011).

The sayings are popular in China: "Players in the same industry are enemies," and "If the master teaches all nuances to an apprentice, the master will get starved." People may regard these sayings as taken-for-granted. However, such belief in people may lead to the lack of learning within workforce. At the same time, the management and governance literature in the Western countries often emphasize transparency, assuming that transparency ensures justice and efficiency. Ethan S. Bernstein (2012) from Harvard University conducted rigorous studies in a Chinese factory with both participative observation and field experiment. He found that the first-line employees learn from one another on skills and knowhow; however, when transparency is required where their interactions are observable to others, the employees stop emitting their knowledge to others.

Chi-yue Chiu and Ying-yi Hong made wonderful use of the context of Hong Kong where they started to work two decades ago. They studied the transition of individuals' dominant cultural paradigm (Hong \& Chiu, 2001; Hong, Morris, Chiu, \& Benet-Martinez, 2000; Knowles, Morris, Chiu, \& Hong, 2001). The young students growing up in Hong Kong are simultaneously influenced by Chinese and Western cultures. They found that when seeing the Chinese cultural symbols (e.g., Great Wall, Summer Palace), the Hong Kong students began to think more like Chinese; however, when seeing the Western cultural icons (e.g., the Statue of Liberty, Mount Rushmore), the Hong Kong students began to think like Westerners. Based on the empirical findings, they started a new stage of cultural research — previous studies mainly compare the "means" of individuals from different cultures, but from their work, culture is understood not as static dimensions but as dynamic knowledge structure. The series of work is significantly advancing the mainstream cultural research in recent years.

It is widely known that Chinese are very superstitious and often submissively accept their own fates (Tsang, 2004). However, accepting fate necessarily restricts people to change their environment and lives. The paradox led Evelyn Au and ZhiXue Zhang (Au et al., 2011; 2012; Au, Qin, \& Zhang, in press) to start their research on this topic. They found that the most successful leaders are those who admit their fates but at the same time are agentic to change their fortunes. They synthesized the two aspects into a single concept, negotiable fate, to capture the idea that some people believe that their fates are actually negotiable as long as they can act agentically.

Across a number of studies, they successfully establish the construct, and the management implications are also very concrete. 
Put together, these successful examples demonstrate that the Chinese indigenous research is promising, but at the same time, rigorous (mainstream Western) approaches are also necessary. We believe that if scholars closely watch the management practices in China, they may be able to identify the "special" practices different from the "mainstream" management literature and therefore grasp the chances for making theoretical contributions to global management knowledge. Toward that goal, we need to get close to Chinese companies, talking often with their people including executives, managers, and employees. Doing so may enable us to identify interesting and relevant research questions (Abrahamson, 2008). We need to design and implement empirical studies with open-mind without assuming that the traditional "mainstream" data collection (e.g., questionnaires) and analytical skills (e.g., regression) are sufficient. We need also to continuously fine tune our researches by travelling between theories and data. In sum, when we are really excited about what we study and we do so in rigorous ways, we will make the academia different.

\section{Acknowledgements}

We thank Professor David Ahlstrom and the anonymous reviewers for their constructive comments. Any errors that may remain are our own.

The research was partially supported by Chinese Natural Science Foundation Committee (No. 71372021), a project granted to the second author. 


\section{References}

Abrahamson, E. 2008. 22 things I hate: Mini rants on management research. Journal of Management Inquiry, 17(4): 422-425.

Acemoglu, D. \& Robinson, J. 2012. Why nations fail: The origins of power, prosperity, and poverty. New York: Crown Business.

Ahlstrom, D. 2010. Innovation and growth: How business contributes to society. Academy of Management Perspectives, 24(3): 11-24.

Ahlstrom, D. 2015. From the Editors: Publishing in the Journal of World Business. Journal of World Business, 50(2): 251-255.

Ahlstrom, D. 2017. How to publish in academic journals: Writing a strong and organized introduction section. Journal of Eastern European and Central Asian Research, 4(2): 1-9.

Ahlstrom, D., Bruton, G. D., \& Lui, S. S. Y. 2000. Navigating China's changing economy: Strategies for private firms. Business Horizons, 43(1): 5-15.

Ahlstrom, D., Bruton, G. D., \& Zhao, L. 2013. Turning good research into good publications. Nankai Business Review International, 4(2): 92-106.

Ahlstrom, D., Chen, S. J., \& Yeh, K. S. 2010. Managing in ethnic Chinese communities: Culture, institutions, and context. Asia Pacific Journal of Management, 27(3): 341-354.

Ahlstrom, D., Lamond, D., \& Ding, Z. 2009. Reexamining some management lessons from military history. Asia Pacific Journal of Management, 26(4): 617-642.

Ahlstrom, D., Levitas, E., Hitt, M. A., Dacin, M. T., \& Zhu, H. 2014. The three faces of China: Strategic alliance partner selection in three ethnic Chinese economies. Journal of World Business, 49(4): 572-585.

Ahlstrom, D., Nair, A., Young, M. N., \& Wang, L. C. 2006. China: Competitive myths and realities. SAM Advanced Management Journal, 71(4): 4-10.

Ahlstrom, D., \& Wang, L. C. 2010. Entrepreneurial capitalism in East Asia: How history matters. In H. Landstrom \& F. Lohrke (Eds.), Historical foundations of entrepreneurship research: 406-427. Northampton, MA: Edward Elgar.

Au, E. W. M., Chiu, C.-Y., Chaturvedi, A., Mallorie, L. A., Viswanathan, M., Zhang, Z.-X., \& Savani, K. 2011. Maintaining faith in agency under immutable constraints: Cognitive consequences of believing in negotiable fate. International Journal of Psychology, 46(6): 463-474.

Au, E. W. M., Chiu, C.-Y., Zhang, Z.-X., Mallorie, L. A., Chaturvedi, A., Viswanathan, M., \& Savani, K. 2012. Negotiable fate: Social ecological foundation and psychological functions. Journal of Cross-Cultural Psychology, 43(6): 931942.

Au, E. W. M., Qin, X., \& Zhang, Z.-X. In press. Beyond personal control: When and how executives' beliefs in negotiable fate foster entrepreneurial orientation and firm performance. Organizational Behavior and Human Decision Processes.

Bartha, P. 2016. Analogy and analogical reasoning. In E. N. Zalta (Ed.). The Stanford Encyclopedia of Philosophy (Winter 2016 Edition). Stanford, CA: The Metaphysics Research Lab, Center for the Study of Language and Information, Stanford University. 
Berggren, D. 1962. The use and abuse of metaphor, I. The Review of Metaphysics, 16(2): 237-258.

Berggren, D. 1963. The use and abuse of metaphor, II. The Review of Metaphysics, 16(3): 450-472.

Bernstein, E. S. 2012. The transparency paradox: A role for privacy in organizational learning and operational control. Administrative Science Quarterly, 57(2): 181-216.

Bruton, G. D., Peng, M. W., Ahlstrom, D., Stan, C., \& Xu, K. (2015). State-owned enterprises around the world as hybrid organizations. Academy of Management Perspectives, 29(1), 92-114.

Bruton, G. D., Zahra, S. A., \& Cai, L. (forthcoming). Examining entrepreneurship through indigenous lenses. Entrepreneurship: Theory and Practice, published online on November 22, 2017

Colquitt, J. A., \& Zapata-Phelan, C. P. 2007. Trends in theory building and theory testing: A five-decade study of the Academy of Management Journal. Academy of Management Journal, 50(6): 1281-1303.

Christensen, C. M., Raynor, M., McDonald, R. 2015. What is disruptive innovation? Harvard Business Review, 93 (12), 44-53.

Danesi, M. 1993. Vico, metaphor, and the origin of language. Indianapolis: Indiana University Press.

DiMaggio, P. J., \& Powell, W. W. 1983. The iron cage revisited: Institutional isomorphism and collective rationality in organizational fields. American Sociological Review, 48(2):147-160.

Domar, E. 1946. Capital expansion, rate of growth, and employment, Econometrica, 14(2): 137-147.

Donaldson, L. 1995. American anti-management theories of organization: A critique of paradigm proliferation. Cambridge: Cambridge University Press.

Fang, T. 2003. A critique of Hofstede's fifth national culture dimension. International Journal of Cross-cultural Management, 3(3): 347-368.

Fang, T. 2010. Asian management research needs more self-confidence: Reflection on Hofstede (2007) and beyond. Asia Pacific Journal of Management, 27(1): 155-170.

Fang, T. 2012. Yin Yang: A new perspective on culture. Management and organization Review, 8(1): 25-50.

Garud, R., \& Ahlstrom, D. 1997. Technology assessment: a socio-cognitive perspective. Journal of Engineering and Technology Management, 14(1): 25-48.

Gentner, D. 2003. Analogical Reasoning, Psychology of. In Vol. 1 of Encyclopedia of Cognitive Science: 106-112. London: Nature Publishing Company.

Gentner, D., \& Jeziorski, M. 1993. The shift from metaphor to analogy in Western science. In A. Ortony (Ed.). Metaphor and thought (2nd ed.): 447-480. Cambridge, UK: Cambridge University Press.

Gibson, C. B., \& Birkinshaw, J. 2004. The antecedents, consequences, and mediating role of organizational ambidexterity. Academy of Management Journal, 47(2): 209226.

Hambrick, D. C. 1994. 1993 Presidential Address: What if the Academy actually mattered? Academy of Management Review, 19(1): 11-16. 
Harrod, R. F. 1939. An essay in dynamic theory, The Economic Journal, 49(193): 1433.

Hillman, A. J., \& Hitt, M. A. 1999. Corporate political strategy formulation: A model of approach, participation, and strategy decisions. Academy of Management Review, 24(4): 825-842.

Hong, Y.-Y., \& Chiu, C.-Y. 2001. Toward a paradigm shift: From cross-cultural differences in social cognition to social-cognitive mediation of cultural differences. Social Cognition, 19: 181-196.

Hong, Y.-Y., Morris, M. W., Chiu, C.-Y., \& Benet-Martinez, V. 2000. Multicultural minds: A dynamic constructivist approach to culture and cognition. American Psychologist, 55(7): 709-720.

Huang, X., \& Bond, M. H. (Eds.). 2012. Handbook of Chinese organizational behavior: Integrating theory, research and practice. Edward Elgar Publishing. Huang, Y. 2010. Debating China's economic growth: The Beijing Consensus or the Washington Consensus. Academy of Management Perspectives, 24(2): 31-47.

Isaacson, W. 2011. Steve Jobs. New York: Simon \& Schuster.

Jia, L., You, S., \& Du, Y. 2012. Chinese context and theoretical contributions to management and organization research: A three - decade review. Management and Organization Review, 8(1), 173-209.

Jia, N. 2016. Political strategy and market capabilities: Evidence from the Chinese private sector. Management and Organization Review, 12(1): 75-102.

Jing, R., \& Van de Ven, A. H. 2014. A Yin-Yang model of organizational change: The case of Chengdu bus group. Management and Organization Review, 10(1): 29-54.

Knowles, E. D., Morris, M. W., Chiu, C.-y., \& Hong, Y.-Y. 2001. Culture and process of person perception: Evidence for automaticity among East Asians in correcting for situational influences on behavior. Personality and Social Psychology Bulletin, 27: 1344-1356.

Lai, J. Y., Lam, L. W., \& Liu, Y. 2010. Do you really need help? A study of employee supplication and job performance in China. Asia Pacific Journal of Management, 27(3): 541-559.

Leung, K., \& Brew, F. P. 2009. A cultural analysis of harmony and conflict: Toward an integrative model of conflict styles. In R.S. Wyer, C.-y. Chiu, \& Y.-y. Hong (Eds.), Understanding culture: Theory, research and application: 411-428. New York: Psychology Press.

Leung, K., Brew, F. P., Zhang, Z. X., \& Zhang, Y. 2011. Harmony and conflict: A cross-cultural investigation in China and Australia. Journal of Cross-Cultural Psychology, 42(5): 795-816.

Leung, K., Koch, P. T., \& Lu, L. 2002. A dualistic model of harmony and its implications for conflict management in Asia. Asia Pacific Journal of Management, 19(2-3): 201-220.

Lewis, W. A. 1954. Economic development with unlimited supplies of labor. The Manchester School, 22(2): 139-91.

Li, H., \& Zhang, Y. 2016. Integrating contextual knowledge and generalizable theory: How can Chinese management research make theoretical contributions? (情境化 
知识与普适化理论的有机结合——探索中国管理学研究的理论创新之道). Quarterly Journal of Management (管理学季刊), 1(4): 1-17 (in Chinese).

Li, H., Meng, L., \& Zhang, J. 2006. Why do entrepreneurs enter politics? Evidence from China. Economic Inquiry, 44(3): 559-578.

Li, P. P. 2012. Exploring the unique roles of trust and play in private creativity: From the complexity-ambiguity-metaphor link to the trust-play-creativity link. Journal of Trust Research, 2(1): 71-97.

Li, P. P. 2013. Indigenous research on Chinese management and Chinese traditional philosophies (中国本土管理研究与中国传统哲学), Chinese Journal of Management (管理学报), 10(9): 1249-1261 (in Chinese).

Li, P. P. 2014. The unique value of Yin - Yang balancing: A critical response. Management and Organization Review, 10(2): 321-332.

Li, P. P. 2016. Global implications of the indigenous epistemological system from the East: How to apply Yin-Yang balancing to paradox management. Cross Cultural \& Strategic Management, 23(1): 42-77.

Li, P. P. forthcoming. The epistemology of Yin-Yang balancing as the root of Chinese cultural traditions: The indigenous features and geocentric implications, in J. Spencer-Rodgers, \& K. Peng (Eds.), The psychological and cultural foundations of dialectical thinking. New York: Oxford University Press.

Li, P. P., Leung, K., Chen, C. C., \& Luo, J. D. (2012). Indigenous research on Chinese management: What and how. Management and Organization Review, 8(1): 7-24.

Li, P. P., Sekiguchi, T., \& Zhou, K. (2016). The emerging research on indigenous management in Asia. Asia Pacific Journal of Management, 33(3): 583-594.

Li, X. 2014. Can Yin-Yang guide Chinese indigenous management research?. Management and Organization Review, 10(1): 7-27.

Li, X. 2016. The danger of Chinese exceptionalism. Management and Organization Review, 12(4): 815-816.

Li, X. H., \& Liang, X. 2015. A Confucian social model of political appointments among Chinese private-firm entrepreneurs. Academy of Management Journal, 58(2): 592-617.

Li, Y., Ashkanasy, N. M., \& Ahlstrom, D. 2014. The rationality of emotions: A hybrid process model of decision-making under uncertainty. Asia Pacific Journal of Management, 31(1): 293-308.

Li, Y., Chun, H., Ashkanasy, N. M., \& Ahlstrom, D. 2012. A multi-level study of emergent group leadership: Effects of emotional stability and group conflict. Asia Pacific Journal of Management, 29(2): 351-366.

Liden, R. C. 2012. Leadership research in Asia: A brief assessment and suggestions for the future. Asia Pacific Journal of Management, 29(2): 205-212.

Luo, Y., \& Child, J. 2015. A composition-based view of firm growth. Management and Organization Review, 11(3): 379-411.

Ma, L., \& Tsui, A. S. 2015. Traditional Chinese philosophies and contemporary leadership. Leadership Quarterly, 26(1): 13-24.

Magee, J. C., \& Galinsky, A. D. 2008. Social hierarchy: The self-reinforcing nature of power and status. The Academy of Management Annals, 2:1, 351-398. 
McCarthy, K. J., Dolfsma, W., \& Weitzel, U. 2016. The first global merger wave and the enigma of Chinese performance. Management and Organization Review, 12(2): 221-248.

McCloskey, D. N. 2010. Bourgeois dignity: Why economics can't explain the modern world. Chicago: University of Chicago Press.

McCloskey, D. N. 2013. Tunzelmann, Schumpeter, and the hockey stick. Research Policy, 42(10): 1706-1715.

Meyer, K. E. 2006. Asian management research needs more self-confidence. Asia Pacific Journal of Management, 23(2): 119-137.

Meyer, K. E. 2014. What the fox says, how the fox works: Deep contextualization as a source of new research agendas and theoretical insights. Management and Organization Review, 10(3): 373-380.

Mintzberg, H. 2004. Managers not MBAs: A hard look at the soft practice of managing and management development. San Francisco: Berrett-Koehler Publishers.

Nair, A., \& Ahlstrom, D. 2003. Delayed creative destruction and the coexistence of technologies. Journal of Engineering and Technology Management, 20(4): 345365.

O’Reilly, C. A., \& Tushman, M. L. 2013. Organizational ambidexterity: Past, present, and future. Academy of Management Perspectives, 27(4): 324-338.

Ortony, A. 1975. Why metaphors necessary and not just nice. Educational Theory, 25: 45-53.

Peng, M. W. 2005. Perspectives - from China strategy to global strategy. Asia Pacific Journal of Management, 22(2): 123-141.

Peng, M. W. 2007. Celebrating 25 years of Asia Pacific management research. Asia Pacific Journal of Management, 24(4): 385-393.

Pylyshyn, Z. W. 1993. Metaphorical imprecision and the "top-down" research strategy. In A. Ortony (Ed.). Metaphor and thought (2nd ed.): 543-558. Cambridge, UK: Cambridge University Press.

Romer, P. M. 1986. Increasing returns and long-run growth. Journal of Political Economy, 94(5): 1002-1037.

Romer, P. M. 1990. Endogenous technological change. Journal of political Economy, 98(5, Part 2), S71-S102.

Scott, W. R. 2013. Institutions and organizations: Ideas, interests, and identities. Thousand Oaks, CA: Sage Publications.

Shenkar, O. 2017. Management research with Chinese characteristics(具有中国特色 的管理学研究). Quarterly Journal of Management (管理学季刊), 2(1): 1-11.

Singh, K. 2007. The limited relevance of culture to strategy. Asia Pacific Journal of Management, 24(4), 421-428.

Solow, R. M. 1956. A contribution to the theory of economic growth. Quarterly Journal of Economics, 70(1): 65-94.

Solow, R. M. 1957. Technical change and the aggregate production function. Review of Economics and Statistics, 39(3): 312-320.

Sutton, R. I., \& Staw, B. M. 1995. What theory is not. Administrative Science 
Quarterly, 40, 371-384.

Tsang, E. W. K. 2004. Superstition and decision-making: Contradiction or complement? Academy of Management Executive, 18(4): 92-104.

Tsui, A. S. 2004. Contributing to global management knowledge: A case for high quality indigenous research. Asia Pacific Journal of Management, 21(4): 491-513.

Tsui, A. S. 2006. Contextualization in Chinese management research. Management and Organization Review, 2(1): 1-13.

Tsui, A. S. \& Lyu, L. 2015. The theoretical and practical issues in Chinese indigenous management research (中国本土管理研究的理论与实践问题: 对徐淑英的访 谈), Chinese Journal of Management (管理学报), 12(3): 313-321 (in Chinese).

Van de Ven, A. H. 1989. Nothing is quite so practical as a good theory. Academy of Management Review, 14(4): 486-489.

Van de Ven, A. H. 2007. Engaged scholarship: A guide for organizational and social research. Oxford: Oxford University Press

Wang, X., \& Li, P. P. 2017. A conceptual framework of "Wu"-based innovation at the team level: A case study on indigenous innovation in the context of aerospace projects (团队悟性创新理论框架: 中国航天工程情境下的本土创新案例研究), Foreign Economics \& Management (外国经济与管理), 39(3):3-23 (in Chinese).

Wang, Y. 2008. Public diplomacy and the rise of Chinese soft power. Annals of the American Academy of Political and Social Science, 616: 257-273,

Weber, M. 1978. The nature of social action. In Runciman, W. G., \& Mathews, E. (Eds.), Max Weber: Selections in translation:7-32. Cambridge, UK: Cambridge University Press.

Weick, K. E. 1989. Theory construction as disciplined imagination. Academy of Management Review, 14(4): 516-531.

White, S. 2002. Rigour and relevance in Asian management research: Where are we and where can we go? Asia Pacific Journal of Management, 19(2/3): 287-352.

Xiao, Z., \& Tsui, A. S. 2007. When brokers may not work: The cultural contingency of social capital in Chinese high-tech firms. Administrative Science Quarterly, 52: $1-31$.

Yang, H., \& Zhao, D. 2015. Performance legitimacy, state autonomy and China's economic miracle. Journal of Contemporary China, 24(91): 64-82.

Young, M. N , Peng, M. W., Ahlstrom, D., \& Bruton, G. D. 2003. Principal-Principal Agency. Web Journal of Chinese Management Review, 6(1): 18-45.

Zhang, Y., Waldman, D., Han, Y. L., Li, X. B. 2015. Paradoxical leader behavior in people management: Antecedents and consequences. Academy of Management Journal, 58, 538-566.

Zhang, Z.-X., Ju, D., \& Ma, L. 2014. State of the science of organizational behavior research: A brief review and future direction for Chinese research. Acta Psychologica Sinica, 46 (2): 265-284. (张志学, 鞠冬, 马力。组织行为学研究 的现状：意义与建议。《心理学报》2014 年 (第 46 卷) 第 2 期, 265-284 页。)

Zhao, D. 2009. The mandate of heaven and performance legitimation in historical and contemporary China. American Behavioral Scientist, 53(3): 416-433. 
Zhao, L., Gu, H., Yue, C., \& Ahlstrom, D. 2013. Consumer welfare and GM food labeling: A simulation using an adjusted Kumaraswamy distribution. Food Policy, 42(C): 58-70.

Zheng, L. 2012. How far are Chinese economists from winning a Noble Prize?

Changjiang Business Newspaper, October 15. (郑良中. 中国经济学家离诺贝尔 奖有多远，长江商报, available: http://news.xinhuanet.com/fortune/201210/15/c_123824737.htm_(in Chinese).

Zhou, X., \& Wei, Q. 2015. Zhou Xueguang: The logic of Chinese state governance (周雪光: 中国国家治理的逻辑), cnpolitics.org, available at: http://cnpolitics.org/2015/08/logic_of_chinese_governing/(in Chinese). 